Оригинальная статья/Original article

УДК 664.3.033

DOI: http://doi.org/10.20914/2310-1202-2017-1-28-33

Оптимизация процесса отжима растительного масла методом математического моделирования

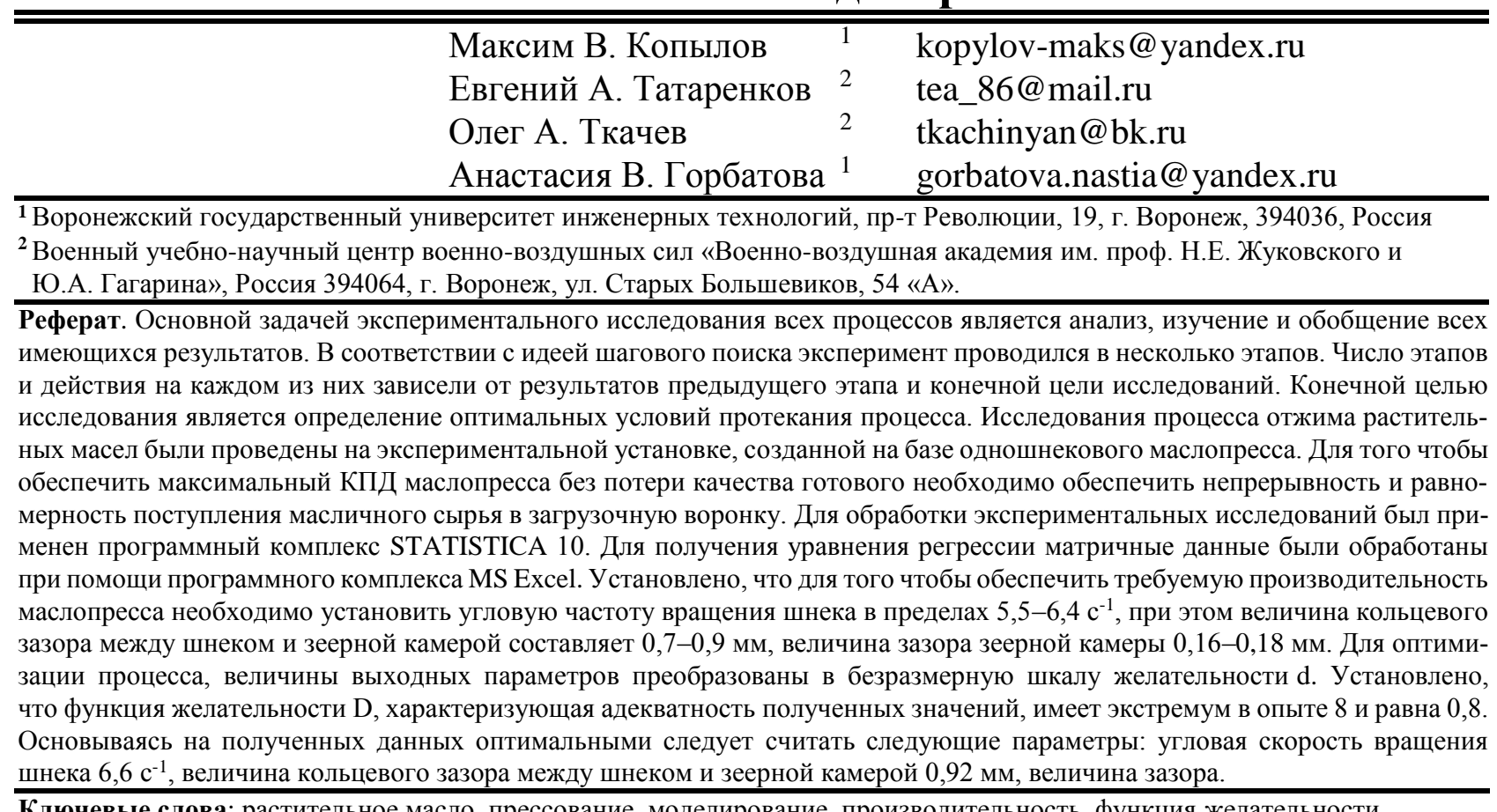
Ключевые слова: растительное масло, прессование, моделирование, производительность, функция желательности

\title{
Optimization of oil extraction process by the mathematical modeling
} method

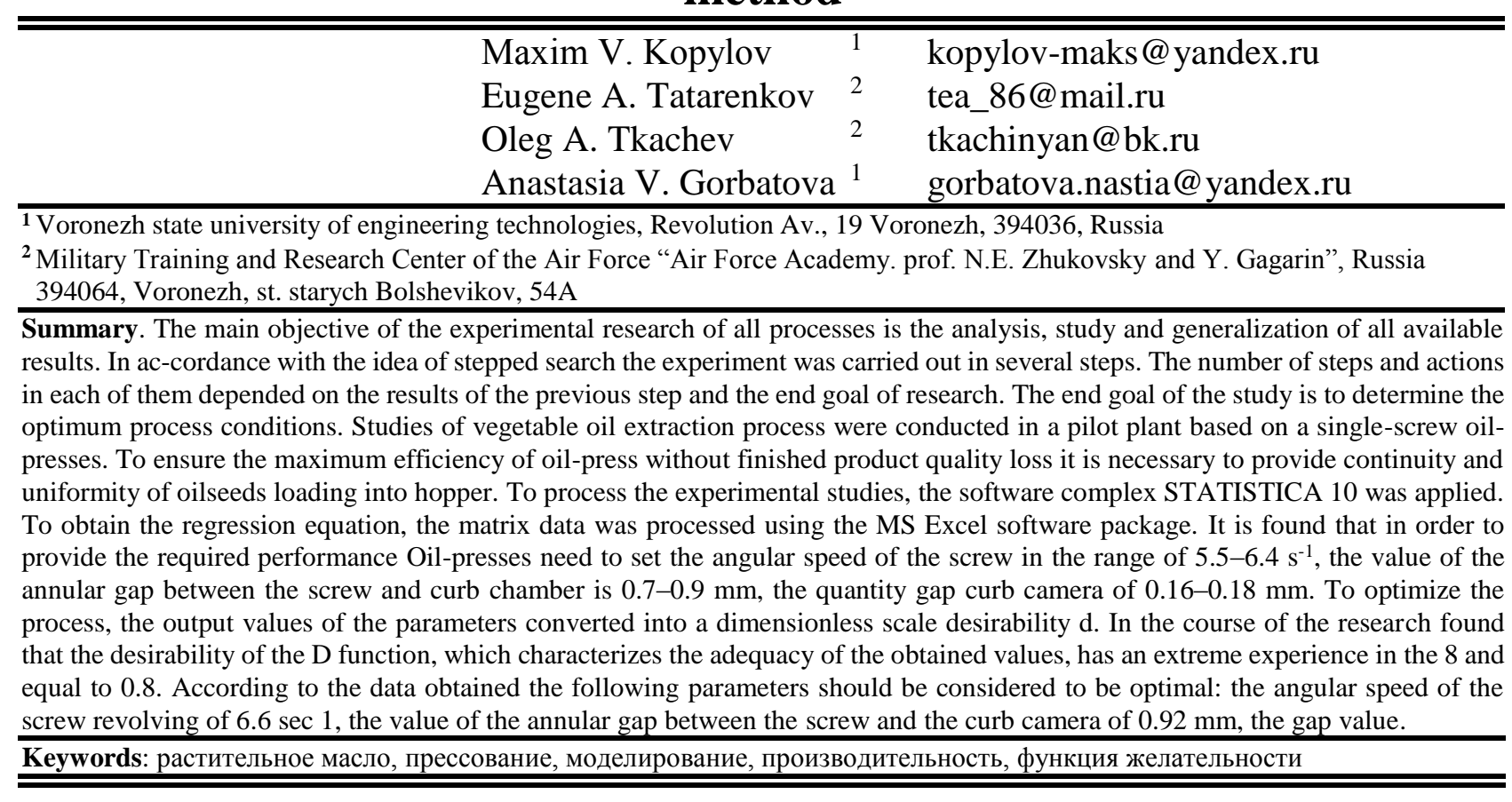

\section{Для цитирования}

Копылов М.В., Татаренков Е.А., Ткачев О.А., Горбатова А.В. Оптимизация процесса отжима растительного масла методом математического моделирования // Вестник ВГУИТ. 2017. Т. 79. № 1. C. 28-33. doi:10.20914/2310-1202-2017-1-28-33
For citation

Kopylov M. V., Tatarenkov E. A., Tkachev O. A., Gorbatova A. V. Optimization of oil extraction process by the mathematical modeling method. Vestnik VGUIT [Proceedings of VSUET]. 2017. Vol. 79. no. 1. pp. 28-33. (in Russian). doi:10.20914/2310-1202-2017-1-28-33 28 


\section{Введение}

Основной задачей экспериментального исследования всех процессов является анализ, изучение и обобщение всех имеющихся результатов. Полученные данные могут охватывать либо малый диапазон значений, или обширный, на которых строятся первые этапы моделирования. При выполнении поставленной задачи, предварительно составляется перечень имеющихся факторов, из которых необходимо исключить малозначимые. На основе вышесказанного завершается предварительная подготовка к экспериментальной части [1-3].

\section{Материалы и методы}

$\mathrm{B}$ соответствии с идеей шагового поиска эксперимент проводился в несколько этапов. Число этапов и действия на каждом из них зависели от результатов предыдущего этапа и конечной цели исследований. Конечной целью исследования является определение оптимальных условий протекания процесса отжима растительного масла (рисунок 1).

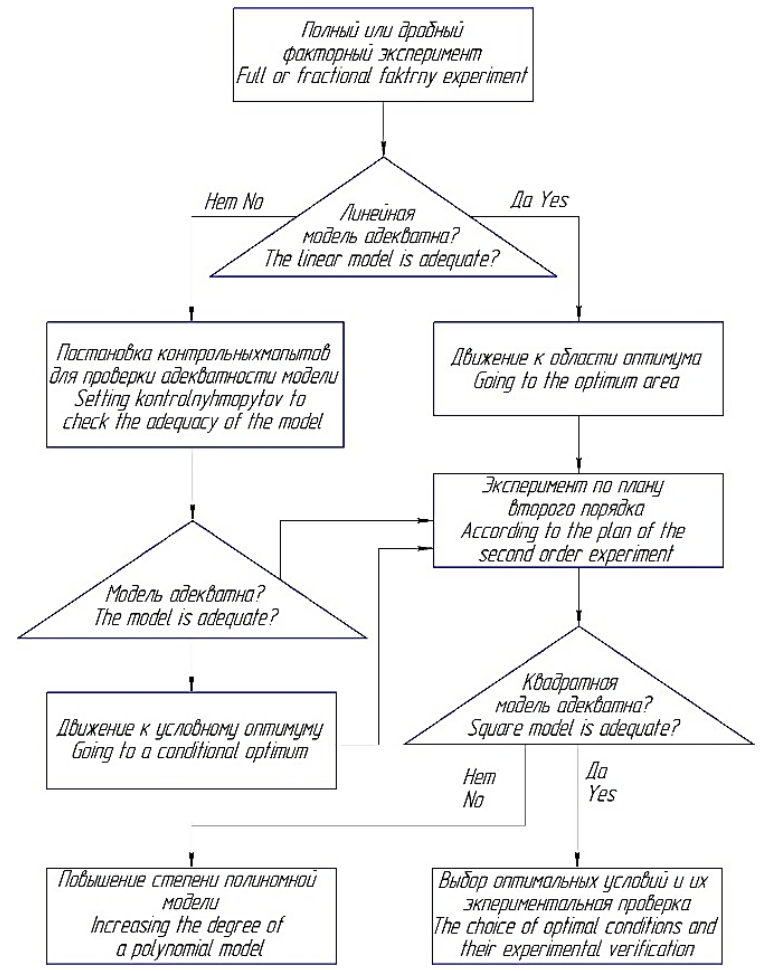

Рисунок 1. Структурная схема экспериментальных исследований с целью оптимизации процесса отжима растительного масла

Figure 1. Block diagram of experimental research in order to optimize oil extraction process

В качестве основных факторов были выбраны: $\mathrm{X}_{1}$ - частота вращения шнека маслопресса, об/с; $\mathrm{X}_{2}$ - величина зазора зеерной камеры, м; $\mathrm{X}_{3}$ - величина кольцевого зазора между шнеком и зеерной камерой, м. Выбранные факторы совместимы и некоррелируемы между собой.
В таблице 1 представлены данные для определения условий опыта. Результаты экспериментальных исследований приведены в таблице 2. Общее число опытов $\mathrm{N}=18$, число опытов в центре плана $\mathrm{N}_{0}=6$, число факторов $\mathrm{k}=3$, плечо «звёздной» точки $\mathrm{r}=1,682$.

В качестве функции отклика выбрано $\mathrm{Y}_{1}$ - производительность маслопресса, кг/ч.

Растительные масла, получаемые на этом оборудовании, могут быть также использованы в качестве рецептурных составляющих для других жировых продуктов [4-6].

Исследования процесса отжима растительных масел были проведены на экспериментальной установке (рисунок 2), созданной на базе одношнекового маслопресса. Экспериментальная установка состоит из источника электропитания 1 (380 В), щита управления 2; загрузочного бункера 3 , органа, регулирующего зазор 4 между шнеком и зеерной камерой 5 , станины 6 , сборника масла 7 , электропривода 8 .

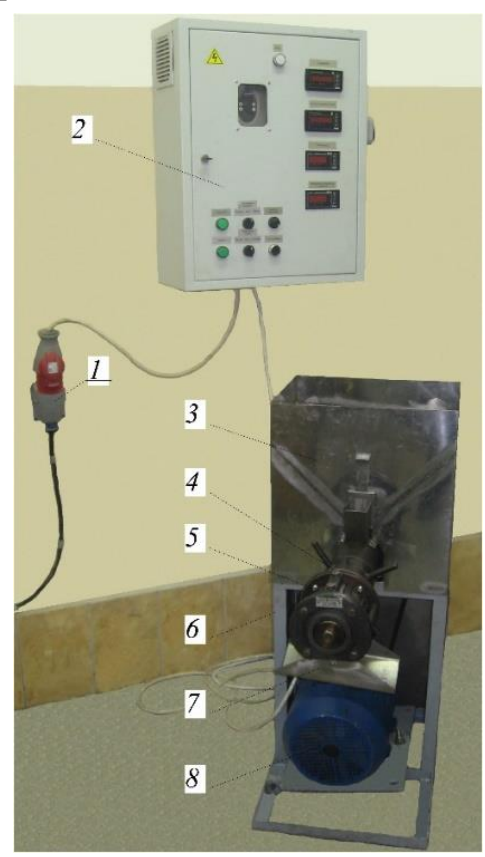

Рисунок 2. Экспериментальная установка МПЭ-1

Figure 2. Experimental installation MBE-1

При помощи витков шнека исходное масличное сырье перемещается внутри зеерной камеры, которая состоит из зеерных пластин с зазорами не более 0,5 мм. Конструкция рабочей камеры от загрузочного бункера до выхода жмыха изготовлена таким образом, что пространство между шнеком и внутренней частью корпуса постепенно уменьшается, приводя тем самым к уплотнению продукта и способствуя началу сжатия материала в результате чего повышается давление, которое влечет за собой начало выхода масла. После разделения исходного продукта на жидкую (масло) и твердую фазу (жмых) масло просачивается сквозь узкие каналы, образованные 
зеерными пластинами, а жмых выходит из маслопресса через кольцевой зазор, образованный шнеком и зеерной камерой.

Для того чтобы обеспечить максимальный КПД маслопресса без потери качества готового продукта (количество осадка в масле, сохранение термолабильных органических веществ) необходимо обеспечить непрерывность и равномерность поступления масличного сырья в загрузочную воронку [7-8].

Для обработки экспериментальных исследований был применен программный комплекс STATISTICA 10. Для получения уравнения регрессии матричные данные были обработаны при помощи программного комплекса MS Excel.

Уравнение регрессии в физических переменных после удаления незначимых коэффициентов имеет вид:

$$
\begin{aligned}
& Y_{1}=62.55+0.64 X_{1}+0.66 X_{2}+0.5 X_{3}+0.15 X_{1} X_{2}+ \\
& +0.25 X_{1} X_{3}+0.13 X_{2} X_{3}+10.01 X_{1}^{2}+9.96 X_{2}^{2}+9.96 X_{3}^{2} \\
& Q, k r / 4=1975,4376-1,2531 E 7^{\star} x-270,9363^{+} y+3,564 E 10^{*} x^{*} x+16974,744^{\star} x^{*} y+22,4199^{*} y^{\star} y
\end{aligned}
$$

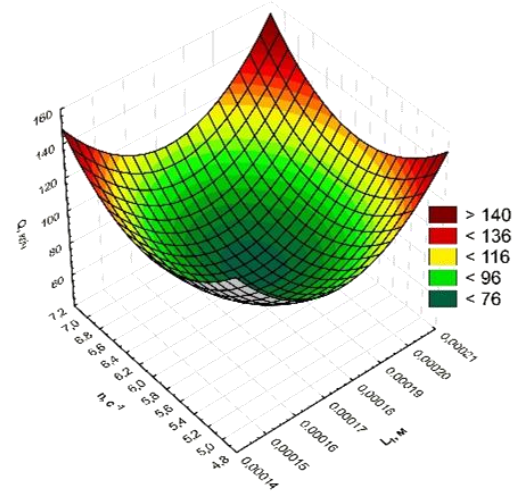

Рисунок 3. Название на русском языке Влияние частоты вращения шнека и величины зазора зеерной камеры на производительность маслопресса

Figure 3. The impact speed of the screw and the size of the gap curb camera performance Oil-presses

$Q, k F / 4=1517,6396-1,2467 E 7^{*} x^{*}-8,975 E 5^{*} y+3,559 E 10^{*} x^{*} x+6,9314 E 7^{*} x^{*} y+5,5596 E 8^{*} y^{*} y$

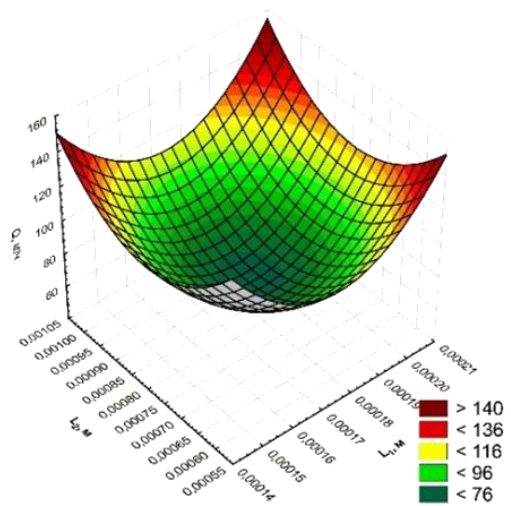

Рисунок 4. Влияние величины кольцевого зазора между шнеком и камерой и величины зазора зеерной камеры на производительность маслопресса

Figure 4. Effect of the annular gap between the screw and the chamber, and the chamber gap value curb performance Oil-presses

$Q, k r / 4=1243,6964-270,754^{*} x-9,0759 E 5^{*} y+22,4189^{*} x^{*} x+3501,0409^{*} x^{*} y+5,5672 E 8^{*} y^{*} y$

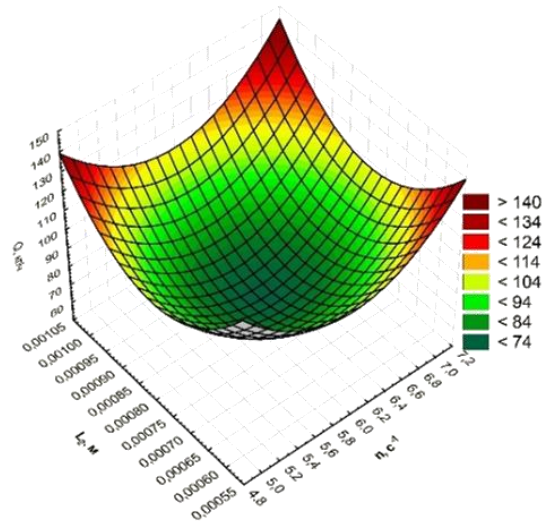

Рисунок 5. Название на русском языке Влияние частоты вращения шнека и величины кольцевого зазора между шнеком и камерой на производительность маслопресса

Figure 5. Effect of screw speed and the size of the annular clearance between the screw and chamber performance Oil-presses

Таблица 1 .

Матрица планирования и результаты экспериментальных исследований процесса отжима растительного масла

\begin{tabular}{|c|c|c|c|c|c|c|c|c|c|c|c|}
\hline \multirow{3}{*}{ № } & \multirow{2}{*}{\multicolumn{9}{|c|}{$\begin{array}{l}\text { Область факторного пространства } \\
\text { The domain of the quotient space }\end{array}$}} & \multirow{2}{*}{\multicolumn{2}{|c|}{$\begin{array}{c}\text { Выходные параметры } \\
\text { Output parameters } \\
\text { Выход готового продукта, кг/ч } \\
\text { Output of finished product, } \mathrm{kg} / \mathrm{h}\end{array}$}} \\
\hline & & & & & & & & & & & \\
\hline & $X_{1}$ & $\mathrm{X}_{2}$ & $\mathrm{X}_{3}$ & $\mathrm{X}_{1} \mathrm{X}_{2}$ & $\mathrm{X}_{1} \mathrm{X}_{3}$ & $\mathrm{X}_{2} \mathrm{X}_{3}$ & $\mathrm{X}_{1}^{2}$ & $\mathrm{X}_{2}{ }^{2}$ & $\mathrm{X}_{3}^{2}$ & $\begin{array}{c}\text { Экспериментальные } \\
\text { Experimental }\end{array}$ & $\begin{array}{l}\text { Pacчётные } \\
\text { Calculated }\end{array}$ \\
\hline 1 & 2 & 3 & 4 & 5 & 6 & 7 & 8 & 9 & 10 & 11 & 12 \\
\hline 1 & -1 & -1 & -1 & 1 & 1 & 1 & 1 & 1 & 1 & 90,40 & 91,22 \\
\hline 2 & -1 & -1 & 1 & 1 & -1 & -1 & 1 & 1 & 1 & 90,60 & 91,47 \\
\hline 3 & -1 & 1 & -1 & -1 & 1 & -1 & 1 & 1 & 1 & 91,20 & 92,00 \\
\hline 4 & -1 & 1 & 1 & -1 & -1 & 1 & 1 & 1 & 1 & 92,80 & 92,74 \\
\hline 5 & 1 & -1 & -1 & -1 & -1 & 1 & 1 & 1 & 1 & 91,50 & 91,70 \\
\hline 6 & 1 & -1 & 1 & -1 & 1 & -1 & 1 & 1 & 1 & 93,60 & 92,94 \\
\hline 7 & 1 & 1 & -1 & 1 & -1 & -1 & 1 & 1 & 1 & 93,80 & 93,08 \\
\hline 8 & 1 & 1 & 1 & 1 & 1 & 1 & 1 & 1 & 1 & 95,50 & 94,81 \\
\hline 9 & $-1,682$ & 0 & 0 & 0 & 0 & 0 & 2,828 & 0 & 0 & 91,20 & 89,80 \\
\hline 10 & 1,682 & 0 & 0 & 0 & 0 & 0 & 2,828 & 0 & 0 & 90,80 & 91,95 \\
\hline
\end{tabular}

Table 1.

Planning Matrix and the results of experimental studies of the vegetable oil pressing process 
Продолжение табл. 1

\begin{tabular}{|c|c|c|c|c|c|c|c|c|c|c|c|}
\hline 1 & 2 & 3 & 4 & 5 & 6 & 7 & 8 & 9 & 10 & 11 & 12 \\
\hline 11 & 0 & $-1,682$ & 0 & 0 & 0 & 0 & 0 & 2,828 & 0 & 90,30 & 89,61 \\
\hline 12 & 0 & 1,682 & 0 & 0 & 0 & 0 & 0 & 2,828 & 0 & 91,40 & 91,85 \\
\hline 13 & 0 & 0 & $-1,682$ & 0 & 0 & 0 & 0 & 0 & 2,828 & 90,50 & 89,89 \\
\hline 14 & 0 & 0 & 1,682 & 0 & 0 & 0 & 0 & 0 & 2,828 & 91,20 & 91,56 \\
\hline 15 & 0 & 0 & 0 & 0 & 0 & 0 & 0 & 0 & 0 & 93,80 & 62,56 \\
\hline 16 & 0 & 0 & 0 & 0 & 0 & 0 & 0 & 0 & 0 & 93,80 & 62,56 \\
\hline 17 & 0 & 0 & 0 & 0 & 0 & 0 & 0 & 0 & 0 & 93,80 & 62,56 \\
\hline 18 & 0 & 0 & 0 & 0 & 0 & 0 & 0 & 0 & 0 & 93,80 & 62,56 \\
\hline
\end{tabular}

\section{Результаты и обсуждение}

Из рисунков 3-5 видно, что для обеспечения требуемой производительности маслопресса необходимо установить угловую частоту вращения шнека в пределах 5,5-6,4 c-1, при этом величина кольцевого зазора между шнеком и зеерной камерой составляет 0,7-0,9 мм, величина зазора зеерной камеры $0,16-0,18$ мм.

Учитывая, что все исследуемые факторы однозначно влияют на выход готового продукта, было проведено исследование по определению оптимальных условий процесса (методом Харрингтона).

Для оптимизации процесса величины выходных параметров преобразованы в безразмерную шкалу желательности $d\left(d_{1}-\right.$ выход готового продукта).

Для оценки полученных расчетных данных воспользуемся количественным, универсальным показателем качества - обобщенной функцией желательности D. По максимальному значению, которого можно определить оптимальные параметры процесса.

Согласно формуле:

$$
Y=b_{0}+\sum b_{i} x_{i}+\sum b_{i k} x_{i} x_{k}+\sum b_{i i} x_{i}^{2}
$$

где $b_{0}$ - свободный член уравнения, представляет среднюю величину отклика при условии, что исследуемые факторы располагаются на средних, «нулевых» уровнях; $i, k-$ индексы факторов; $b_{i}-$ коэффициенты при линейных членах; $b_{i k}-$ коэффициенты двухфакторных взаимодействий, показывают изменение степени влияния одного фактора на величину изменения другого; $\mathrm{b}_{\mathrm{ii}}$ - коэффициенты квадратичных эффектов, показывают нелинейность выходного параметра от рассматриваемых факторов.

Система уравнений для определения $b_{0}$ и $b_{1}$ для выхода готового продукта примет вид:

$$
1,51=b_{0}+94,81 b_{1}-0,46=b_{0}+62,56 b_{1}
$$

где 94,81 - лучшее значение для $V_{1}(\%)$; 62,56худшее значение для $V_{1}(\%)$.

Отсюда $b_{0}=-4,276$ и $b_{1}=0,061$.

В рассматриваемом случае это уравнение можно ограничить выходными параметрами следующего вида $Y \leq Y_{\max }$ или $Y \geq Y_{\min }$.

Предпочтительной формой преобразования Y в d служит экспоненциальная зависимость:

$$
d=\exp \left[-\exp \left(-Y^{\prime}\right)\right]
$$

где $Y^{\prime}=b_{0}+b_{1} Y$.

Частные функции имеют следующий вид:

$$
d_{1}=\exp \left[-\exp \left(-4,276+0,061 Y_{1}\right)\right]
$$

Значения частных функций желательности для всех точек плана, определенные по этим формулам, приведены в таблице 2. Наглядное представление значений обобщенной функции желательности представлено на рисунке 6.

\begin{tabular}{|c|c|c|c|c|c|}
\hline № & $\mathrm{X}_{1}$ & $\mathrm{X}_{2}$ & $\mathrm{X}_{3}$ & $d_{1}$ & $D$ \\
\hline 1 & -1 & -1 & -1 & 0,759036 & 0,76 \\
\hline 2 & -1 & -1 & 1 & 0,76221 & 0,76 \\
\hline 3 & -1 & 1 & -1 & 0,768823 & 0,77 \\
\hline 4 & -1 & 1 & 1 & 0,777795 & 0,78 \\
\hline 5 & 1 & -1 & -1 & 0,765099 & 0,77 \\
\hline 6 & 1 & -1 & 1 & 0,780169 & 0,78 \\
\hline 7 & 1 & 1 & -1 & 0,781818 & 0,78 \\
\hline 8 & 1 & 1 & 1 & 0,80133 & 0,80 \\
\hline 9 & $-1,682$ & 0 & 0 & 0,740335 & 0,74 \\
\hline 10 & 1,682 & 0 & 0 & 0,768205 & 0,77 \\
\hline 11 & 0 & $-1,682$ & 0 & 0,737745 & 0,74 \\
\hline 12 & 0 & 1,682 & 0 & 0,766967 & 0,77 \\
\hline 13 & 0 & 0 & $-1,682$ & 0,741555 & 0,74 \\
\hline 14 & 0 & 0 & 1,682 & 0,763344 & 0,76 \\
\hline 15 & 0 & 0 & 0 & 0,20519 & 0,21 \\
\hline 16 & 0 & 0 & 0 & 0,20519 & 0,21 \\
\hline 17 & 0 & 0 & 0 & 0,20519 & 0,21 \\
\hline 18 & 0 & 0 & 0 & 0,20519 & 0,21 \\
\hline
\end{tabular}

Таблица 2.

Значения частных функций и обобщенной функции желательности каждого опыта

The values of private functions and generalized functions desirability of each experiment

Для связи с редакцией: post@ vestnik-vsuet.ru 


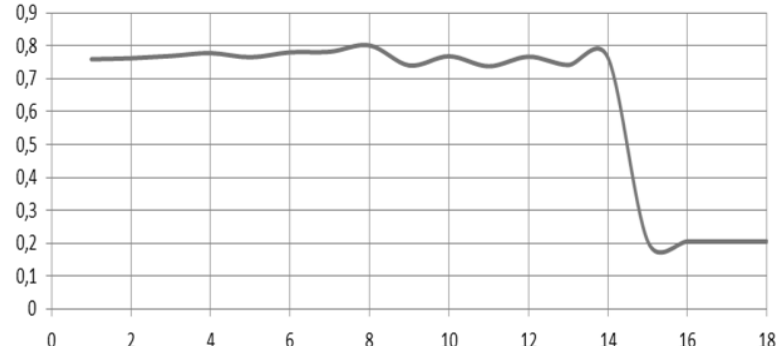

Рисунок 6. Обобщенная функция желательности (D) Figure 6. The generalized function desirability of (D)

\section{ЛИТЕРАТУРА}

1 Остриков А. Н., Слюсарев М. И., Горбатова А. В., Шендрик Т. А. Диффузионная модель перемешивания сливочно-растительных спредов // Вестник ВГУИТ. 2015. № 3. С. 7-12.

2 Василенко В.Н., Фролова Л.Н., Михайлова Н.А., Русина К. Ю., Слюсарев М. И. Моделирование процесса отжима масличного сырья в форпрессе // Хранение и переработка сельхозсырья. 2016. № 9. С. 5-9.

3 Анферов С. Д., Скульский О. И., Славнов Е. В. Математическое моделирование процесса прямого отжима масличной культуры // Вестник ПНИПУ. 2014. № 1. С. 31-56.

4 Василенко Л. И., Фролова Л. Н., Драган И. В., Мошкина С. В. Создание купажей функциональных растительных масел с длительным сроком хранения // Вестник ВГУИТ. 2013. № 3. С. 121-124.

5 Остриков А. Н., Смирных А. А., Горбатова А. В. Комплексное исследование реологических свойств спреда функциональной направленности // Вестник Алтайского государственного аграрного университета. 2013. № 1. С. 93-96.

6 Вараксин С. В., Неретина Е. А., Доценко С. М., Соболев Р. В., Маркин Д. А., Обоснование параметров процесса получения соево-кукурузного белково-углеводного гранулята // Вестник Бурятской государственной сельскохозяйственной академии им. 2016. № 3. С. 107-117.

7 Фролова Л.Н., Василенко В.Н., Драган И.В. Михайлова Н.А Изучение закономерностей предварительной экструзионной подготовки масличных культур к процессу прессования // Вестник ВГУИТ. 2015. № 2. С. 27-29.

8 Фролова Л. Н., Василенко В. Н., Драган И. В., Дерканосова А. А., Михайлова Н. А. Эксергетический анализ линии комплексной двухступенчатой переработки масличных культур // Вестник Международной академии холода. 2015. № 4. С. 78-84.

9 Nkongho R.N., Ncnanji Y., O. Tataw, Levang P. Less oil but more money! Artisanal palm oil milling in Cameroon// African Journal of Agricultural Research. 2014. C. $1586-1596$.

10 Sorin-Stefan B., Ionescu M., Voicu G., Ungureanu N., Vladut V. Calculus Elements for Mechanical Presses in Oil Industry // Food Industry. 2013. C. 471-489.

11 Ali N. Olive Oil Production in a Semi-Arid Area: Evidence from Roman Tell Es-Sukhnah, Jordan // Mediterranean Archaeology and Archaeometry. 2014. T. 14. №. 2. C. 337-348.

\section{Заключение}

Установлено, что функция желательности D, характеризующая адекватность полученных значений имеет экстремум в опыте 8 и равна 0,8 . В основании данного результата оптимальными следует считать параметры: угловая скорость вращения шнека $6,6 \mathrm{c}^{-1}$, величина кольцевого зазора между шнеком и зеерной камерой 0,92 мм, величина зазора зеерной камеры 0,19 мм.

12 Rodrigues J. et al. Modeling and optimization of laboratory-scale conditioning of Jatropha curcas L. seeds for oil expression // Industrial Crops and Products. 2016. T. 83. C. 614-619.

13 Moses D. R. Performance evaluation of continuous screw press for extraction soybean oil // American journal of science and technology. 2014. T. 1. №. 5. C. 238-242.

14 Фролова Л.Н., Василенко В.Н., Драган И.В., Дерканосова А.А., Михайлова Н.А. Эксергетический анализ линии комплексной двухступенчатой переработки масличных культур // Вестник Международной академии холода. 2015. № 4. С. 78-84.

15 Пилипенко Т.В., Нилова Л.П., Пилипенко Н.И. Возможность использования электрофизических методов для идентификации и контроля качества растительных масел // Вестник Южно-Уральского государственного университета. Серия: Пищевые и биотехнологии. 2014. Т. 2. № 2. С. 41-49.

\section{REFERENCES}

1 Ostrikov A. N., Slyusarev M. I., Gorbatova A. V., Shendrik T. A. Diffusion model the mixing of cream and vegetable spreads. Vestnik VGUIT [Proceedings of VSUET]. 2015. no. 3. pp. 7-12. (in Russian).

2 Vasilenko V. N., Frolova L. N., Mikhailova N. A., Rusina K. Yu., Slyusarev M. I. Modeling of process of extraction of raw materials in fortresse. Khranenie $i$ pererabotka sel'khozsyr'ya [Storage and processing of agricultural products]. 2016. no. 9. pp. 5-9. (in Russian).

3 Anferov S. D., Skul'skii O. I., Slavnov E. V. Mathematical modeling of the process of direct extraction of oilseeds. Vestnik PNIPU [Bulletin of Perm State Technical University. Mechanics]. 2014. no. 1. pp. 31-56. (in Russian).

4 Vasilenko L. I., Frolova L. N., Dragan I. V., Moshkina S. V. Create functional blends of vegetable oils with a long shelf life. Vestnik VGUIT [Proceedings of VSUET]. 2013. no. 3. pp. 121-124. (in Russian).

5 Ostrikov A. N., Smirnykh A. A., Gorbatova A. V. A comprehensive study of the rheological properties of the spread functional orientation. Vestnik Altaiskogo gosudarstvennogo agrarnogo universiteta [Bulletin of Altai state agrarian University]. 2013. no. 1. pp. 93-96. (in Russian).

6 Varaksin S. V., Neretina E. A., Dotsenko S. M., Sobolev R. V., Markin D. A., Justification of parameters of the process of obtaining soy-corn protein-carbohydrate granules. Vestnik Buryatskoi gosudarstvennoi sel'skokhozyaistvennoi akademii [Bulletin of the Buryat state Academy of agriculture]. 2016. no. 3. pp. 107-117. (in Russian). 
7 Frolova L. N., Vasilenko V. N., Dragan I. V. Mikhailova N. A study of the patterns of pre-extrusion preparation for oilseed crops to the pressing process. Vestnik VGUIT [Proceedings of VSUET]. 2015. no. 2.pp. 27-29. (in Russian).

8 Frolova L. N., Vasilenko V. N., Dragan I. V., Derkanosova A. A., Mikhailova N. A. Exergy analysis of the integrated two-stage processing of oilseeds. Vestnik Mezhdunarodnoi akademii kholoda [Bulletin of the International Academy of refrigeration]. 2015. no. 4. pp. 78-84. (in Russian).

9 Nkongho R.N., Ncnanji Y., O. Tataw, Levang P. Less oil but more money! Artisanal palm oil milling in Cameroon. African Journal of Agricultural Research. 2014. pp. 1586-1596.

10 Sorin-Stefan B., Ionescu M., Voicu G., Ungureanu N., Vladut V. Calculus Elements for Mechanical Presses in Oil Industry. Food Industry. 2013. pp. 471-489.

11 Ali N. Olive Oil Production in a Semi-Arid Area: Evidence from Roman Tell Es-Sukhnah, Jordan. Mediterranean Archaeology and Archaeometry. 2014. vol. 14. no. 2. pp. 337-348.

\section{СВЕДЕНИЯ ОБ АВТОРАХ}

Максим В. Копылов к. т. н., доцент, кафедра технологии жиров, процессов и аппаратов химических и пищевых производств, Воронежский государственный университет инженерных технологий, пр-т Революции, 19, г. Воронеж, 394036, Россия, kopylov-maks@yandex.ru

Евгений А. Татаренков к. т. н., преподаватель, кафедра общепрофессиональных дисциплин, Военный учебно-научный центр военно-воздушных сил «Военно-воздушная академия им. проф. Н.Е. Жуковского и Ю.А. Гагарина», ул. Старых Большевиков, 54 «А», г. Воронеж, 394064,Россия, tea_86@mail.ru Олег А. Ткачев к.т.н., преподаватель, кафедра общепрофессиональных дисциплин, Военный учебно-научный центр военно-воздушных сил «Военно-воздушная академия им. проф. Н.Е. Жуковского и Ю.А. Гагарина», ул. Старых Большевиков, 54 «А», г. Воронеж, 394064, Россия, tkachinyan@bk.ru

Анастасия В. Горбатова к. т. н., старший преподаватель, кафедра технологии жиров, процессов и аппаратов химических и пищевых производств, Воронежский государственный университет инженерных технологий, пр-т Революции, 19, г. Воронеж, 394036, Россия, gorbatova.nastia@yandex.ru

\section{КРИТЕРИЙ АВТОРСТВА}

Максим В. Копылов обзор литературных источников по исследуемой проблеме, провёл эксперимент, выполнил расчёты Евгений А. Татаренков предложил методику проведения эксперимента

Олег А. Ткачев консультация в ходе исследования Анастасия В. Горбатова написала рукопись, корректировала её до подачи в редакцию и несёт ответственность за плагиат

КОНФЛИКТ ИНТЕРЕСОВ

Авторы заявляют об отсутствии конфликта интересов.

ПОСТУПИЛА 13.01.2017

ПРИНЯТА В ПЕЧАТЬ 01.02.2017
12 Rodrigues J. et al. Modeling and optimization of laboratory-scale conditioning of Jatropha curcas L. seeds for oil expression. Industrial Crops and Products. 2016. vol. 83. pp. 614-619.

13 Moses D. R. Performance evaluation of continuous screw press for extraction soybean oil. American journal of science and technology. 2014. vol. 1. no. 5. pp. 238-242.

14Frolova L.N., Vasilenko V.N., Dragan I.V., Derkanosova A.A., Mikhailova N.A. Exergetic analysis of the line of complex two-stage processing of oilseeds Vestnik Mezhdunarodnoi akademii kholoda [Bulletin of the International academy of refrigeration] 2015, no. 4, pp. 78-84 (in Russian)

15 Pilipenko T.V., Nilova L.P., Pilipenko N.I. The possibility of using electrophysical methods for identification and quality control of vegetable oils Vestnik YuzhnoUral'skogo gosudarstvennogo universiteta [Proceedings of the South Ural State University. Series: Food and biotechnology] 2014, vol. 2, no. 2, pp. 41-49. (in Russian)

\section{INFORMATION ABOUT AUTHORS}

Maxim V. Kopylov candidate of technical sciences, assistant professor, fat technology, processes and devices of chemical and food industries department, Voronezh state university of engineering technologies, Revolution Av., 19 Voronezh, 394036, Russia, kopylov-maks@yandex.ru

Eugene A. Tatarenkov candidate of technical sciences, lecturer, general professional disciplines department, Military training and research center of the air force "Air force academy. prof. N.E. Zhukovsky and Y. Gagarin”, starych Bolshevikov str., 54A, Voronezh, 394064, Russia, tea_86@mail.ru

Oleg A. Tkachev candidate of technical sciences, lecturer, general professional disciplines department, Military training and research center of the air force "Air force academy. prof. N.E. Zhukovsky and Y. Gagarin", starych Bolshevikov str., 54A, Voronezh, 394064, Russia, tkachinyan@bk.ru

Anastasia V. Gorbatova candidate of technical sciences, senior lecturer, fat technology, processes and devices of chemical and food industries department, Voronezh state university of engineering technologies, Revolution Av., 19 Voronezh, 394036, Russia, gorbatova.nastia@yandex.ru

\section{CONTRIBUTION}

Maxim V. Kopylov review of the literature on an investigated problem, conducted an experiment, performed computations Eugene A. Tatarenkov proposed a scheme of the experiment

Oleg A. Tkachev consultation during the study

Anastasia V. Gorbatova wrote the manuscript, correct it before filing in editing and is responsible for plagiarism

\section{CONFLICT OF INTEREST}

The authors declare no conflict of interest.

RECEIVED 1.13.2017

ACCEPTED 2.1.2017 